\title{
BMJ Open Factors associated with healthcare workers willingness to participate in disasters: a cross-sectional study in Sana'a, Yemen
}

\author{
Weiam Al-Hunaishi (D) , ${ }^{1}$ Victor CW Hoe, ${ }^{1}$ Karuthan Chinna ${ }^{1,2}$
}

To cite: Al-Hunaishi W, Hoe VCW, Chinna K. Factors associated with healthcare workers willingness to participate in disasters: a cross-sectional study in Sana'a, Yemen. BMJ Open 2019;9:e030547. doi:10.1136/ bmjopen-2019-030547

- Prepublication history and additional material for this paper are available online. To view these files, please visit the journal online (http://dx.doi org/10.1136/bmjopen-2019030547).

Received 05 April 2019 Revised 04 September 2019 Accepted 24 September 2019

Check for updates

(c) Author(s) (or their employer(s)) 2019. Re-use permitted under CC BY-NC. No commercial re-use. See rights and permissions. Published by BMJ.

${ }^{1}$ Department of Social and Preventive Medicine, Faculty of Medicine, University of Malaya, Kuala Lumpur, Malaysia

${ }^{2}$ School of Medicine-SRI,

Taylor's University, Subang Jaya, Malaysia

Correspondence to

Dr Weiam Al-Hunaishi;

waam59@hotmail.com

\section{ABSTRACT}

Objectives Willingness to participate in disasters is usually overlooked and not addressed in disaster preparedness training courses to ensure health service coverage. This will lead to issues during the disaster's response. This study, therefore, aims to assess healthcare workers willingness to participate in biological and natural disasters, and to identify its associated factors.

Design This is a cross-sectional study using a selfadministered questionnaire. The questionnaire was distributed to 1093 healthcare workers. The data were analysed using multiple logistic regression with significance level $p<0.05$. Ethical clearance and consent of the participants were duly obtained.

Setting In three public hospitals that provide tertiary-leve healthcare in Sana'a City, Yemen.

Participants There were 692 nurses and doctors (response rate $63.3 \%$ ) completed the questionnaires. Results Almost half of the participants $55.1 \%$ were nurses and $44.9 \%$ were doctors. The study found that self-efficacy was associated with willingness to participate in disaster response for any type of disasters (OR 1.319, $95 \% \mathrm{Cl} 1.197$ to 1.453 ), natural disasters (OR 1.143, $95 \%$ $\mathrm{Cl} 1.069$ to 1.221) and influenza pandemic (OR 1.114, $95 \% \mathrm{Cl} 1.050$ to 1.182). The results further show that willingness is associated with healthcare workers being young, male and having higher educational qualifications. Conclusion Self-efficacy has been found to be an important factor associated with willingness. Improving self-efficacy through training in disaster preparedness may increase willingness of healthcare workers to participate in a disaster.

\section{INTRODUCTION}

In various parts of the world, disasters destroy communities and infrastructures, causing huge material and human losses. ${ }^{1}$ Similarly, hospitals and health centres are also affected by the disasters, which restrict its work of relieving disaster-stricken communities. By 2025, more than half of the world population will live in cities, particularly in urban cities located along seismic fault lines, flood and other natural disaster-prone areas. ${ }^{2}$ Therefore, healthcare workers (HCWs) should be

\section{Strengths and limitations of this study}

- This study is the first study that attempts to assess healthcare workers willingness to participate in different types of disasters in Sana'a City, Yemen.

- Implementing a cross-sectional design and using a convenience sample has made it difficult to establish causal association.

- The study sample represents healthcare workers in Sana'a City in terms of gender and locality.

- The face-to-face approach, which included introduction of the study and its objectives, ensured a higher response rate and minimised the risk of selection bias.

prepared to manage the influx of patients during possibly life-threatening circumstances. A HCW is defined as 'the one who delivers care and services to the sick and ailing either directly as doctors and nurses or indirectly as aides, helpers, laboratory technicians or even medical waste handlers'.

According to the Global Facility for Disaster Reduction and Recovery, Yemen is one of the priority countries in the Middle East and North African region, mainly due to its vulnerability to disasters. ${ }^{4-6}$ Natural disasters, which include storms, landslides, earthquake and floods, are recurrent in Yemen. Floods due to the monsoonal rainfall are responsible for most of the mortality due to disasters. ${ }^{6}$ Currently in Yemen, disaster management mainly focuses on responding to postdisasters damage, and there is a lack of disaster preparedness, such as training and mock drills. The insufficient training makes it difficult to maintain preparedness. ${ }^{48} \mathrm{~A}$ competent prepared HCW could better mitigate and respond to the community health needs during crises, which in turn will elevate health outcomes.

During disasters, HCWs are expected to provide healthcare assistance to people 
suffering from the disasters alongside with caring for their usual patients. Some are also required to care for their dependents. Most of the previous studies reported an anticipated decrease in health workforce during a disaster as not all HCWs are willing to participate in a disaster. Therefore, understanding the factors associated with willingness to participate in a disaster would allow more effective planning for a disaster situation. Systematic reviews have found that willingness was associated with factors like the nature and type of event; competing obligations between personal and professional needs; the work environment and climate including personal safety, and the relationship between knowledge and perceptions of efficacy. ${ }^{9} 10$

Disaster preparedness activities and routine disasters trainings have been found to improve the knowledge, skills and attitude preparedness of disasters. ${ }^{11}$ However, the factors that affect the willingness to participate in disasters are beyond just having knowledge on disaster management. ${ }^{9-12}$

In a recent systematic review, they found only few studies that have been conducted in the Middle East on the willingness to participate in disasters. They recommend that further research should be conducted based on behavioural theories to better understand the Middle East context of willingness to participate in a disaster. ${ }^{13}$ In another systematic review of 70 studies on HCW willingness to participate in disasters, only 12 studies were from Asia and none of those studies were from the Middle East. ${ }^{11}$ Therefore, the objective of this study is to determine the associations between sociodemographic, professional and intrapersonal factors associated with the doctors' and nurses' willingness to participate in disasters response in Sana'a, Yemen. The study factors are built based on the self-efficacy behavioural theory.

\section{METHODS}

\section{Study design, population and instrument}

This is a cross-sectional study conducted in three public hospitals in the Sana'a Governorate, Yemen; Al-Thora, Al-Jumhouri and Al-Kuwait hospitals, which have more than a total of 4000 nurses and doctors, which is the focus of this study. Out of this, 1093 HCWs were selected through convenient sampling by approaching the HCWs individually. The sample size calculation was determined using the OpenEpi software. It was based on a $95 \%$ CI with a power of set to $80 \%$. The sample size of 1093 was determined based on the variable 'perception of responsibility to participate' from a prestudy, which is an element of the self-efficacy construct with the highest sample size to achieve an association. ${ }^{14}$ The determined sample size was 614 , which was inflated by $78 \%$ based on the lowest response rate of previous studies to reach $1093 .{ }^{15}$

The questionnaire was developed by the researcher based on information from previous studies and opinions of national and international experts (online supplementary materials). ${ }^{15-18}$ The questionnaire was pretested for validity and reliability. The questionnaire was distributed to national and international experts together with questions on the validity of the questionnaire with a scale of 1-4 (1 not relevant to 4 highly relevant). It tested the questionnaire's consistency, relatedness, representativeness and clarity of wording. From the results of the pretest, six items of the questionnaire that was related to the knowledge construct, was deleted and changes on the questions were reworded. The revised questionnaires were then forward and backward translated from English to Arabic and from Arabic to English. Following that, three other HCWs were asked to give their opinion on the questions based on the objective of the study.

The final questionnaire was pilot tested on 20 doctors and nurses from a hospital, other than hospitals that have been chosen for the study. The internal consistency was assessed using Cronbach's alpha. Self- efficacy was 0.801 and this is considered good intercorrelation. Therefore, the self-efficacy four items were used in the final survey to build the construct as one of the intrapersonal factors (unpublished).

The questionnaire consists of sociodemographic, professional and intrapersonal factors, and willingness to participate in a disaster. The professional, intrapersonal and willingness questions were measured on a five-point Likert scale ( $1=$ strongly disagree, $2=$ disagree, $3=$ somewhat agree, $4=$ agree and $5=$ strongly agree). A binary variable was created based on 'less or equal two' as low and' more than 2' as high.

\section{Data collection}

Informed consent was obtained from the respondents and confidentiality of personal disclosures was re-assured. The self-administered questionnaires were distributed and retrieved between February and March 2018. A final 767 questionnaires were returned for analyses; 75 questionnaires were omitted due to missing values.

\section{Self-efficacy theory}

The self-efficacy theory was chosen to build the self-efficacy construct as it illustrates beliefs that drive actions to face and solve problems that are faced to achieve the intended goals. In case of disaster, the theory could be applied to HCWs who are coping with fear and threat and adapting new behaviours because of their beliefs in their competences. This belief is derived from their successful performances, observing colleagues and managers positive behaviours, convincing by a superior person, and calming the physiological and emotional pressure caused by the threat. ${ }^{19}$

\section{Statistical analysis}

The data were analysed using SPSS V.22. Descriptive outputs were generated describing the median, IQR, frequency counts and percentages. ${ }^{2}$ test and multiple logistic regression were performed to test the hypothesis of the study on $\mathrm{p}<0.05$ for all statistical tests. The variables selected to be included in the multivariate analysis 
were variables with $\mathrm{p}<0.25$ in the univariate analysis, and gender, age and type of profession were also included.

\section{Patient and public involvement}

Patients and the general public were not involved in the conduct of this research. HCWs were involved during the pilot study in order to test the understanding of the written questionnaire. In addition, data were assessable by the researchers and are stored in a secure file in the computer and online storage.

\section{RESULTS}

\section{Sociodemographics characteristics}

Responses were collected from 692 HCWs (response rate $63.3 \%$ ), where 311 (44.9\%) were doctors and 381 $(55.1 \%)$ were nurses. Most of the female participants were nurses at $64.5 \%$. More doctors $(56.6 \%)$ had $>5$ years of experience at their current place of work, as compared with nurses $(40.9 \%)$. The average age of participants was 31.96 (SD 7.46) years across the two occupations. Out of the $65.9 \%$ who had at least one dependent, that is, having to take care of at least one child, elderly person or both, $73.9 \%$ reported to have support to care for their dependents in a case of a disaster. The percentages were almost equally distributed between doctors and nurses.

\section{Professional and intrapersonal characteristics}

Table 1 describes the sociodemographic, professional, intrapersonal and willingness characteristics of respondents. Only $39.2 \%$ of the HCWs had any previous training in dealing with disasters. This was the same for previous work experience, where only $35.8 \%$ of the participants had previous work experience in a disaster situation.

The doctors and nurses reported a high trust in work safety, in family, in colleague's preparedness to react and in their hospital's preparedness to react in case of a disaster, with trust in colleague's preparedness as the highest percentage (88.3\%). Similarly, HCW had a high median score (median 16; IQR 5) in self-efficacy construct.

\section{Respondents' willingness}

Ninety per cent of the participants expressed high willingness to participate in any type of disasters. However, they were less willing to participate in natural disasters $(77.3 \%)$ and influenza pandemic (66.0\%) (table 1).

\section{Analysis of self-efficacy's factors}

There were four items in the self-efficacy construct. After the data collection, the intercorrelation value of self-efficacy was tested before running the main analysis. The descriptive statistics and interitem correlation values of the self-efficacy construct are presented in table 2.

Based on table 2, there was a moderate level of agreement in all the four items. The highest correlation for each item with at least one other item in the construct was
Table 1 Sociodemographic, professional, intrapersonal and willingness characteristics of respondents

\begin{tabular}{|c|c|c|}
\hline Variable & $\begin{array}{l}\text { Frequency } \\
(n=692)\end{array}$ & $\begin{array}{l}\text { Percentage } \\
(\%)\end{array}$ \\
\hline \multicolumn{3}{|l|}{ Age (years) } \\
\hline$\leq 30$ & 360 & 52.0 \\
\hline $31-45$ & 294 & 42.5 \\
\hline$\geq 46$ & 38 & 5.5 \\
\hline \multicolumn{3}{|l|}{ Gender } \\
\hline Male & 419 & 60.5 \\
\hline Female & 273 & 39.5 \\
\hline \multicolumn{3}{|l|}{ Marital status } \\
\hline Single & 258 & 37.3 \\
\hline Married & 420 & 60.7 \\
\hline Divorce & 8 & 1.2 \\
\hline Widow & 6 & 0.9 \\
\hline \multicolumn{3}{|l|}{ Education level } \\
\hline Diploma & 280 & 40.5 \\
\hline Bachelor & 275 & 39.7 \\
\hline Postgraduate education & 137 & 19.8 \\
\hline Master & 104 & 15.0 \\
\hline Professional & 33 & 4.8 \\
\hline \multicolumn{3}{|l|}{ Profession type } \\
\hline Doctors & 311 & 44.9 \\
\hline Specialist medical practitioner ${ }^{*}$ & 126 & 8.2 \\
\hline General medical practitioner ${ }^{\star}$ & 185 & 26.7 \\
\hline Nurses & 381 & 55.1 \\
\hline \multicolumn{3}{|l|}{ Work duration (years) } \\
\hline$\leq 5$ & 360 & 52 \\
\hline $6-10$ & 213 & 30.8 \\
\hline $11-15$ & 76 & 11.0 \\
\hline$\geq 16$ & 43 & 6.2 \\
\hline \multicolumn{3}{|l|}{ Dependent } \\
\hline With dependent & 456 & 65.9 \\
\hline Elder & 65 & 9.4 \\
\hline Child & 276 & 39.9 \\
\hline Both & 115 & 16.6 \\
\hline No dependent & 236 & 34.1 \\
\hline \multicolumn{3}{|l|}{ Support† } \\
\hline No & 119 & 26.1 \\
\hline Yes & 337 & 73.9 \\
\hline \multicolumn{3}{|l|}{ Previous training $\ddagger$} \\
\hline With previous training & 271 & 39.2 \\
\hline Without previous training & 421 & 60.8 \\
\hline \multicolumn{3}{|l|}{ Previous experience $\neq$} \\
\hline With previous experience & 248 & 35.8 \\
\hline Without previous training & 444 & 64.2 \\
\hline
\end{tabular}


Table 1 Continued

Variable

Frequency Percentage

( $n=692)$

(\%)

Trust in work safety in case of disaster

$\begin{array}{lll}\text { High trust in work safety } & 563 & 81.4 \\ \text { Low trust in work safety } & 129 & 18.6\end{array}$

Trust in family preparedness in case of a disaster

High trust in family $\quad 544 \quad 78.6$

preparedness

Low trust in family $\quad 148 \quad 21.4$

preparedness

Trust in colleague preparedness to react in disaster

$\begin{array}{lcc}\begin{array}{l}\text { High trust in colleague } \\ \text { preparedness }\end{array} & 611 & 88.3 \\ \begin{array}{l}\text { Low trust in colleague } \\ \text { preparedness }\end{array} & 81 & 11.7\end{array}$

\begin{tabular}{|c|c|c|}
\hline \multicolumn{3}{|c|}{ Trust in hospital preparedness to react in disaster } \\
\hline $\begin{array}{l}\text { High trust in hospital } \\
\text { preparedness }\end{array}$ & 522 & 75.4 \\
\hline $\begin{array}{l}\text { Low trust in hospital } \\
\text { preparedness }\end{array}$ & 170 & 24.6 \\
\hline Self-efficacy score (median; IQR) & 16 & 5 \\
\hline \multicolumn{3}{|c|}{ Willingness to participate in any type of disaster } \\
\hline High & 623 & 90.0 \\
\hline Low & 69 & 10.0 \\
\hline
\end{tabular}

Willingness to participate in natural disaster

\begin{tabular}{ccr} 
High & 535 & 77.3 \\
\hline Low & 157 & 22.7 \\
Willingness to participate in influenza and pandemic \\
\hline High & 457 & 66.0 \\
Low & 235 & 34.0 \\
\hline
\end{tabular}

*Break down of doctors role.

†Only for participants with dependants. The percentages are only within participants with dependents.

$\ddagger$ Previous experience and training in disasters.

between 0.3 and 0.9 . In factor analysis, the Kaiser-Meyer-Olkin $(\mathrm{KMO})$ value was $0.658(\mathrm{p}<0.001), \mathrm{KMO}$ value close to 1 , so the variables are suitable for factor analysis. Therefore, a single factor was formed from the four items computed, and it was saved as incentive to be used in further analysis. Accordingly, to calculate the self-efficacy, four questions was asked. The sum outcome of the four answers ranged from 4 to 20 (median 16, IQR 5).

\section{Factors associated with willingness to participate in any type} disaster

There was an association between participants' gender and willingness to participate in any type of disaster, with males being more willing compared with females (crude OR 2.161, 95\% CI 1.307 to 3.573) (table 3). Those with high trust in work safety (crude OR 3.284, 95\% CI 1.937 to 5.567), trust in colleague's preparedness (crude OR $2.592,95 \%$ CI 1.401 to 4.795 ) and self-efficacy (crude OR $1.358 ; 95 \%$ CI 1.247 to 1.479 ) were also found to be more willing to participate in any type of disaster in the univariate analysis (table 3 ).

In the final model, having trust in work safety (adjusted OR 2.535, 95\% CI 1.357 to 4.736) and self-efficacy (adjusted OR 1.319, 95\% CI 1.197 to 1.453) were found to be associated with general willingness with any type of disasters (table 4).

\section{Factors associated with willingness to participate in natural disaster}

In the univariate analysis, there was an association between some of the sociodemographic characteristics (age, gender, education level, type of profession and work duration) with willingness to participate in natural disasters. Participants with bachelor and postgraduate degrees had a higher odd of willingness to participate in natural disasters compared with those with a diploma education. Those in the age group of between 31 and 45 years were found to be more willing when compared with participants who were $\leq 30$ years old. The main intrapersonal factors associated with willingness in natural disasters were participants' trust in colleagues' preparedness in case of a natural disaster and self-efficacy (table 3).

In multivariate, being male (adjusted OR 1.639, 95\% CI 1.102 to 2.439) and self-efficacy (adjusted OR 1.143, 95\% CI 1.069 to 1.221 ) were significantly associated with willingness to participate in natural disasters (table 4).

Factors associated with willingness to participate in influenza pandemic disaster

For willingness to participate in an influenza pandemic, the univariate results revealed that being male, having a dependent with no support (compared with participants without a dependent), having previous experience and

Table 2 Descriptive statistics and interterm correlation for items in self-efficacy

\begin{tabular}{|c|c|c|c|c|c|c|}
\hline \multirow[b]{2}{*}{ Items } & \multicolumn{2}{|c|}{ Descriptive statistics } & \multicolumn{4}{|c|}{ Interitem correlation } \\
\hline & Mean & SD & Item 1 & Item 2 & Item 3 & Item 4 \\
\hline Item 1: ability to perform work & 3.36 & 1.074 & 1.000 & 0.592 & 0.267 & 0.259 \\
\hline Item 3: responsibility to participate & 4.23 & 0.929 & 0.267 & 0.325 & 1.000 & 0.390 \\
\hline Item 4: ability report to work & 4.03 & 1.062 & 0.259 & 0.324 & 0.390 & 1.000 \\
\hline
\end{tabular}


Table 3 Univariate association of crude sociodemographic, professional and intrapersonal characteristics with willingness in any type of disaster, in natural disasters or in influenza pandemic

\begin{tabular}{|c|c|c|c|c|c|c|}
\hline \multirow[b]{2}{*}{ Variable } & \multicolumn{2}{|c|}{$\begin{array}{l}\text { Willingness to participate in } \\
\text { any type of disasters }\end{array}$} & \multicolumn{2}{|c|}{$\begin{array}{l}\text { Willingness to participate in } \\
\text { natural disasters }\end{array}$} & \multicolumn{2}{|c|}{$\begin{array}{l}\text { Willingness to participate in } \\
\text { influenza pandemic }\end{array}$} \\
\hline & $\begin{array}{l}\text { OR } \\
(95 \% \mathrm{Cl})\end{array}$ & $P$ value & $\begin{array}{l}\text { OR } \\
(95 \% \mathrm{Cl})\end{array}$ & $P$ value & $\begin{array}{l}\text { OR } \\
(95 \% \mathrm{Cl})\end{array}$ & $P$ value \\
\hline \multicolumn{7}{|l|}{ Age } \\
\hline$\leq 30$ & 1 & 1 & 1 & 1 & 1 & 1 \\
\hline $31-45$ & 1.056 (0.628 to 1.775$)$ & 0.838 & 1.639 (1.126 to 2.387$)$ & 0.010 & $1.138(0.822$ to 1.576$)$ & 0.437 \\
\hline$\geq 46$ & 0.733 (0.269 to 1.997$)$ & 0.544 & 1.967 (0.798 to 4.850$)$ & 0.142 & 1.354 (0.650 to 2.820$)$ & 0.418 \\
\hline \multicolumn{7}{|l|}{ Gender } \\
\hline Female & 1 & 1 & 1 & 1 & 1 & 1 \\
\hline Male & 2.161 (1.307 to 3.573$)$ & 0.003 & 2.254 (1.571 to 3.234$)$ & $<0.001$ & 1.505 (1.093 to 2.072$)$ & 0.012 \\
\hline \multicolumn{7}{|l|}{ Marital status } \\
\hline Single & 1 & 1 & 1 & 1 & 1 & 1 \\
\hline Married & $0.899(0.532$ to 1.521$)$ & 0.692 & $1.128(0.781$ to 1.629$)$ & 0.521 & $1.090(0.787$ to 1.510$)$ & 0.605 \\
\hline Divorce and widow & 0.615 (0.130 to 2.913$)$ & 0.541 & 1.160 (0.314 to 4.291$)$ & 0.824 & $1.362(0.416$ to 4.466$)$ & 0.610 \\
\hline \multicolumn{7}{|l|}{ Education level } \\
\hline Up to diploma & 1 & 1 & 1 & 1 & 1 & 1 \\
\hline Up to bachelor & $1.380(0.775$ to 2.458$)$ & 0.274 & 1.962 (1.317 to 2.922$)$ & 0.001 & $1.221(0.858$ to 1.738$)$ & 0.268 \\
\hline Up to postgraduate & $0.847(0.450$ to 1.596$)$ & 0.608 & 2.279 (1.351 to 3.842$)$ & 0.002 & 0.998 (0.651 to 1.528$)$ & 0.992 \\
\hline \multicolumn{7}{|l|}{ Profession type } \\
\hline Nurses & 1 & 1 & 1 & 1 & 1 & 1 \\
\hline $\begin{array}{l}\text { General medical } \\
\text { practitioner }\end{array}$ & $1.473(0.781$ to 2.776$)$ & 0.231 & 1.554 (1.013 to 2.384$)$ & 0.044 & 0.756 (0.524 to 1.091$)$ & 0.135 \\
\hline $\begin{array}{l}\text { Specialist medical } \\
\text { practitioner }\end{array}$ & 0.965 (0.507 to 1.835$)$ & 0.913 & 2.407 (1.377 to 4.208$)$ & 0.002 & $0.942(0.614$ to 1.446$)$ & 0.785 \\
\hline
\end{tabular}

Work duration

\begin{tabular}{|c|c|c|c|c|c|c|}
\hline$\leq 5$ & 1 & 1 & 1 & 1 & 1 & 1 \\
\hline $6-10$ & 1.006 (0.563 to 1.798$)$ & 0.983 & 1.079 (0.721 to 1.614$)$ & 0.711 & 0.975 (0.683 to 1.392$)$ & 0.889 \\
\hline $11-15$ & 1.028 (0.438 to 2.415$)$ & 0.949 & 2.337 (1.118 to 4.882$)$ & 0.024 & 1.059 (0.626 to 1.791$)$ & 0.832 \\
\hline$\geq 16$ & 0.456 (0.196 to 1.063$)$ & 0.069 & 0.650 (0.329 to 1.286$)$ & 0.216 & 1.198 (0.603 to 2.379$)$ & 0.606 \\
\hline \multicolumn{7}{|l|}{ Presence of dependent } \\
\hline No dependent & 1 & 1 & 1 & 1 & 1 & \\
\hline $\begin{array}{l}\text { Dependent with no } \\
\text { support }\end{array}$ & 0.673 (0.346 to 1.308$)$ & 0.242 & 1.149 (0.683 to 1.933$)$ & 0.601 & 1.617 (1.000 to 2.612$)$ & 0.050 \\
\hline $\begin{array}{l}\text { Dependent with } \\
\text { support }\end{array}$ & 1.253 (0.707 to 2.222$)$ & 0.439 & 1.305 (0.880 to 1.935$)$ & 0.185 & 1.283 (0.907 to 1.815$)$ & 0.158 \\
\hline \multicolumn{7}{|l|}{ Previous training ${ }^{*}$} \\
\hline No & 1 & 1 & 1 & 1 & 1 & 1 \\
\hline Yes & 1.653 (0.959 to 2.849$)$ & 0.070 & 1.090 (0.756 to 1.573$)$ & 0.644 & $\begin{array}{l}1.147(0.829 \text { to } \\
1.585)\end{array}$ & 0.408 \\
\hline
\end{tabular}

Previous experience*

\begin{tabular}{|c|c|c|c|c|c|c|}
\hline No & 1 & 1 & 1 & 1 & 1 & 1 \\
\hline Yes & $1.216(0.714$ to 2.070$)$ & 0.471 & $0.974(0.673$ to 1.411$)$ & 0.889 & 1.857 (1.317 to 2.619$)$ & $<0.001$ \\
\hline \multicolumn{7}{|c|}{ Trust in work safety } \\
\hline Low & 1 & 1 & 1 & 1 & 1 & 1 \\
\hline High & $\mathbf{3 . 2 8 4}$ (1.937 to 5.567$)$ & $<0.001$ & 1.280 (0.825 to 1.987$)$ & 0.271 & 1.192 (0.800 to 1.774$)$ & 0.388 \\
\hline
\end{tabular}

Trust in family preparedness 
Table 3 Continued

\begin{tabular}{|c|c|c|c|c|c|c|}
\hline \multirow[b]{2}{*}{ Variable } & \multicolumn{2}{|c|}{$\begin{array}{l}\text { Willingness to participate in } \\
\text { any type of disasters }\end{array}$} & \multicolumn{2}{|c|}{$\begin{array}{l}\text { Willingness to participate in } \\
\text { natural disasters }\end{array}$} & \multicolumn{2}{|c|}{$\begin{array}{l}\text { Willingness to participate in } \\
\text { influenza pandemic }\end{array}$} \\
\hline & $\begin{array}{l}\text { OR } \\
(95 \% \mathrm{Cl})\end{array}$ & $P$ value & $\begin{array}{l}\text { OR } \\
(95 \% \mathrm{Cl})\end{array}$ & $P$ value & $\begin{array}{l}\text { OR } \\
(95 \% \mathrm{CI})\end{array}$ & $P$ value \\
\hline Low & 1 & 1 & 1 & 1 & 1 & 1 \\
\hline High & 1.338 (0.756 to 2.369) & 0.317 & $1.292(0.850$ to 1.963$)$ & 0.231 & $0.990(.0674$ to 1.454$)$ & 0.959 \\
\hline High & $2.592(1.401$ to 4.795$)$ & 0.002 & $1.974(1.200$ to 3.246$)$ & 0.007 & 1.392 (0.866 to 2.237) & 0.172 \\
\hline \multicolumn{7}{|c|}{ Trust in hospital preparedness } \\
\hline Low & 1 & 1 & 1 & 1 & 1 & 1 \\
\hline High & 1.392 (0.807 to 2.400$)$ & 0.234 & $1.212(0.810$ to 1.814$)$ & 0.351 & 1.158 (0.807 to 1.663$)$ & 0.426 \\
\hline
\end{tabular}

Bold values: $\mathrm{p}<0.05$

*Previous experience and training in disasters.

†Continuous measure, with one unit increase in self-efficacy.

self-efficacy were associated with willingness to participate in a pandemic (table 3 ).

In the final model, having previous experience (adjusted OR 1.528, 95\% CI 1.058 to 2.207) and self-efficacy (adjusted OR $1.114,95 \%$ CI 1.050 to 1.182 ) were found to be associated with willingness to participate in influenza pandemic (table 4).

\section{DISCUSSION}

The study's main question is to test the strength and direction of the association between the independent variables-sociodemographic, professional and intrapersonal variables-with the variables of willingness to participate in three different types of disasters. The results showed that trust in work safety and self-efficacy were associated with disaster participation willingness after in the multivariate analysis. Gender and self-efficacy were found to be significantly associated with willingness to participate in natural disasters. However, previous experience and self-efficacy were statistically significant with willingness of HCW to participate in an influenza pandemic.

It is difficult to obtain a $100 \%$ participation of HCW even though it is vital in case of disasters. Previous studies suggested that between $65 \%$ and $97 \%$ of HCWs were willing to participate in a natural disaster, and between $54 \%$ and $86 \%$ in an influenza pandemic. ${ }^{11} 162021$ The reason for this difference in the levels of willingness between the two types of disasters is due to the great distinction in their nature. The outcome of the interaction between HCW and the socioenvironmental determinants of these disasters leads to having different willingness levels. According to Connor, the weighted risk resulting from this interaction plays a major role in HCW willingness. ${ }^{10}$ In the case of pandemics, the fear of the inability to control biohazards and watching colleagues acquiring a communicable disease after contact with affected persons was a suggested reason for the low willingness levels. ${ }^{10}$ Another qualitative study in Australia highlighted that in different types of disasters emergency nurses' willingness to attend to work is shaped by the weighted risk to self and surrounding people and the pressure formed from the period dealing with the disaster. ${ }^{12}$ Natural disasters may not directly affect HCW or their families like the influenza pandemic which may be a reason for the higher level of willingness to attend to work compared with pandemics.

The findings of this study are consistent with the previous studies regarding their willingness level to different types of disasters. More HCWs were willing to participate in natural disasters $(77.3 \%)$ as compared with influenza pandemics $(66.0 \%)$. Nevertheless, even though there was a higher percentage of HCW willingness in this study to participate in both types of disasters compared with other studies, Yemen's high vulnerability, due its topography and current economic, political and health status, could affect the country's health status and cause huge adverse health impacts when disasters occur. According to the Vulnerability Matrix, one-third of Yemen's districts are highly vulnerable. ${ }^{5}$

Subsequently, due to the armed conflicts in Yemen that started in early 2015, it has become difficult to deal with any disaster that may occur. According to WHO, the healthcare system in Yemen is in a critical situation with about $50 \%$ of the health facilities in Yemen being either partially or totally damaged as a result of the natural disasters and conflicts. Furthermore, of the 3507 healthcare facilities in Yemen, almost 300 healthcare facilities have been destroyed. ${ }^{52}$ Therefore, any possible decrease in the health work force during disasters in Yemen must be considered. The existing drained health sector is based on a vulnerable health system in terms of its structure 


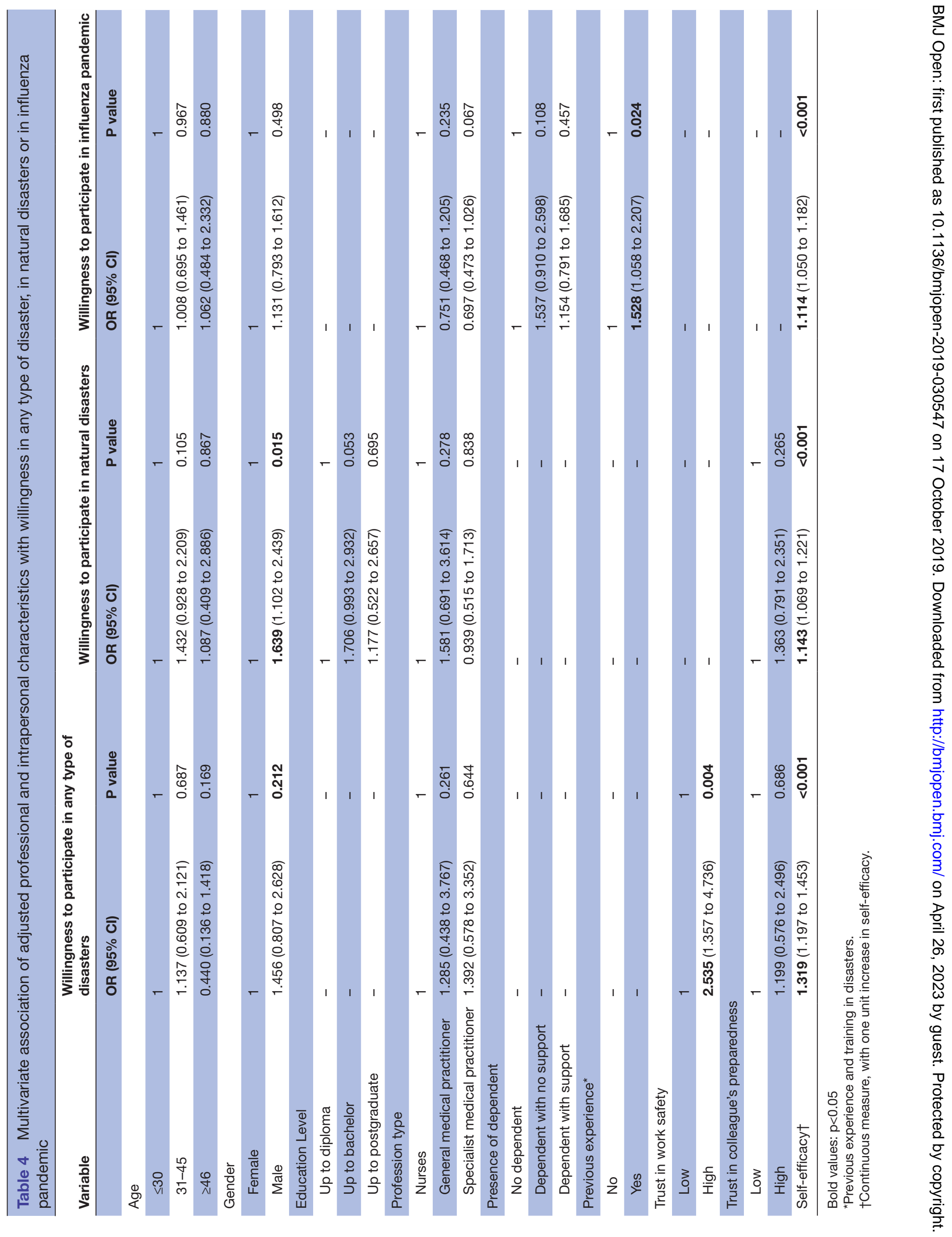


and healthcare staff number and distribution in the country. ${ }^{23}$ Thus, training and preparing healthcare staff to act during disasters is critical and could help achieve Priority 4 in the United Nations' Sendai Framework for Disaster Risk Reduction 2015-2030 in enhancing disaster preparedness for effective response and to 'Build Back Better' in recovery, rehabilitation and reconstruction of disasters, and further prevent any possible humanitarian catastrophe. $^{24}$

The results show that willingness to participate in events of natural disasters may be encouraged by many suggested factors. Factors such as respondents being male are accompanied with higher willingness to participate in natural disasters. The findings are similar to previous studies conducted in Jordan, China and the USA. ${ }^{15162526}$ However, having less female health workers who are willing to participate in disasters highlight a need to address this group during health preparedness programme. This lack in female HCW willingness could be due to the gender and cultural barriers in Yemen. These barriers need to be addressed to better motivate female workers participation in disasters. This is an important area for research as studies on willingness are moving forward.

As noted in the previous studies, nurses and doctors with previous experience in influenza pandemics are ever willing to participate in influenza pandemics. ${ }^{1425}$ HCWs who have experience working with previous disaster have a better knowledge in disaster management, copping strategies and ways to protect themselves and their families, which may be a reason for having higher odds of willingness to participate. According to Alzahrani et al, most of the nurses have a higher level in Mass gatherings management such as communicating effectively during emergencies in Saudi Arabia due to previous experience. ${ }^{27} \mathrm{He}$ also found a need for further trainings by the nurses. Similarly, Chokshi et al found that simulation training, attending conferences and previous experience increase paediatric surgeons' feeling of preparedness. ${ }^{14}$

This study found that the trust in work safety during any type of disaster plays a key role in the willingness to participate, which is similar to the results from previous studies. ${ }^{112528}$ Work safety is important in order for HCW to feel safe and do their work. A study by Stergachis $e t$ al found that the majority of the participants reported their fear or concern for self in case of influenza pandemic and during earthquake scenarios as one of the major barriers to willingness to participate. ${ }^{29}$ In Yemen, work safety in disaster preparedness is concerning after notifications made by Aladhrai $e t$ al and Naser $e t$ al on the current low work place safety and the needs of increasing safety and security standards in Yemen's Health establishments. ${ }^{78}$ Whether it is external or internal catastrophe, unsafe work place could lead to increase optional absenteeism during disaster. Thus, disseminating information on work safety and protection devices during several types of disasters is advisable.

Many studies have established the association between self-efficacy and willingness to participate in disasters. ${ }^{101516}$
Similarly, this study has identified that self-efficacy plays an important role in the willingness to participate in natural disasters, in influenza pandemic and any type of disasters. It indicates that elements tested for self-efficacy like participants increase in familiarity with their role, responsibility to react, and being confident of their ability to deal with various types of disasters could be a key factor to increase HCW self-efficacy. Thus, their willingness to participate will also increase. Disaster preparedness trainings are encouraged to contain materials that explain the responses to the different types of disasters, doctors' and nurses' role in disasters and how it makes a difference in responding to disasters. Supportive measures to increase HCW self-efficacy such as immediate communication with much needed information and rewards for efforts in disasters are suggested.

Although the study faced challenges in the collection of data during the political unrest in the country, data were collected from three of the major public hospitals. The quality of data was ensured by researcher explaining the study and its objectives and answering any questions that may arise. This prevented differences in understanding the questions and increased participants' inclusion in the study. All in all, the study suggested the vital value of increasing self-efficacy and its elements in order to obtain more willingness participants.

\section{Strengths and limitations}

This is the first study to explore the patterns and associated factors of the willingness status to participate in disasters among HCWs in Yemen. The response rate was also high as the questionnaire was distributed personally by the researcher. The questionnaire was pilot tested to ensure the validity of the questionnaire.

This study had some limitations. As the study was performed under a political insecurity/fragile state of the country and a list of workers of HCW working at the hospitals was difficult to obtain. As a result, a universal sample was undertaken, which could limit the study of representativeness. This is a cross-sectional study using a self-administered questionnaire, where the actual willingness of the respondents cannot be ascertained. The respondents may answer positively due to social desirability bias. Other than the self-administrated questionnaire limitations, the findings of the study are limited to staff working at the tertiary-level public hospitals in urban areas of Yemen.

\section{CONCLUSION}

Increasing the likelihood of willingness to participate in disasters plays a key role in guarantying the optimum number of work force. This study indicates that one's sociodemographic, professional and intrapersonal factors play a role in increasing his/her willingness in general and across different types of disasters. Significant differences were revealed between participants' willingness in natural disasters by gender and self-efficacy, and participant's willingness in influenza pandemics by previous experience 
and self-efficacy. This result suggests integrating disaster management to doctors' and nurses' in the early stages of their educational curriculums. This could be achieved by adding early exposure of HCWs to relevant disaster experiences, which would further boost their willingness to participate in disaster response.

Other areas for preparedness may include increasing hospitals safety and resilience; hence that willingness to participate in natural disasters' response was influenced by the demographic characteristic of the healthcare personnel. Additionally, others found outside the bracket should be motivated to participate with a reward package such as incentives and hazard allowance. Further studies should also be conducted in both urban and rural settings with a relatively peaceful atmosphere.

Acknowledgements We thank Dr. Susan Connor, Dr. Karen Hammad and Dr. Mohammed Khalil for their support and advice during the study development, all of the University Malaya academic staff, the team who collected the data, and all the participants who took part in this study.

Contributors WA-H: conceptualised the study, conducted the data collection, analysis and interpretation of data for the work; draft and approve the manuscript for publication. VH: conceptualised the study, interpretation of data for the work; revise and approve the manuscript for publication. KC: conceptualised the study, supervised the data analysis, interpretation of data for the work.

Funding The authors have not declared a specific grant for this research from any funding agency in the public, commercial or not-for-profit sectors.

Competing interests None declared.

Patient consent for publication Not required.

Ethics approval Ethical approval was obtained from the Ministry of Health and Population of Yemen.

Provenance and peer review Not commissioned; externally peer reviewed.

Data availability statement This is an anonymous gathered survey; the data are the responses from the participants. The data have been grouped and presented in the manuscript.

Open access This is an open access article distributed in accordance with the Creative Commons Attribution Non Commercial (CC BY-NC 4.0) license, which permits others to distribute, remix, adapt, build upon this work non-commercially, and license their derivative works on different terms, provided the original work is properly cited, appropriate credit is given, any changes made indicated, and the use is non-commercial. See: http://creativecommons.org/licenses/by-nc/4.0/.

\section{ORCID iD}

Weiam Al-Hunaishi http://orcid.org/0000-0002-5230-3754

\section{REFERENCES}

1 United Nations Economic and Social Commission for Asia and the Pacific. Disasters in Asia and the Pacific: 2015 year in review. United nations report. Economic and social Commission for Asia and the Pacific, 2015. Available: https://www.unescap.org/resources/ disasters-asia-and-pacific-2015-year-review

2 Below R, Wirtz A, Guha-Sapir D. Disaster category classification and peril terminology for operational purposes. centre for research on the epidemiology of disasters, 2009. Available: https://www.cred.be/ node/564

3 Joseph B, Joseph M. The health of the healthcare workers. Indian J Occup Environ Med 2016;20:71-2.

4 Ministry of Water and Environment. Yemen: national progress report on the implementation of the Hyogo framework for action (20132015), 2015. Available: http://preventionweb.net/go/40141

5 World Health Organization. WHO annual report 2017: Yemen. Cairo: WHO Regional Office for the Eastern Mediterranean, 2018Licence: CC BYNC-SA 3.0 IGO.
6 Banerjee A, Bhavnani R, Burtonboy $\mathrm{CH}$, et al. Natural disasters in the middle East and North Africa: a regional overview. The International bank for reconstruction and development. The World Bank, 2014: 101Report No: 81658.

7 Aladhrai SA, Djalali A, Della Corte F, et al. Impact of the 2011 revolution on hospital disaster preparedness in Yemen. Disaster Med Public Health Prep 2015;9:396-402.

8 Naser WN, Ingrassia PL, Aladhrae S, et al. A study of hospital disaster preparedness in South Yemen. Prehosp Disaster Med 2018;33:133-8.

9 Chaffee M. Willingness of health care personnel to work in a disaster: an integrative review of the literature. Disaster Med Public Health Prep 2009;3:42-56.

10 Connor SB. When and why health care personnel respond to a disaster: the state of the science. Prehosp Disaster Med 2014;29:270-4.

11 Gowing JR, Walker KN, Elmer SL, et al. Disaster preparedness among health professionals and support staff: what is effective? an integrative literature review. Prehosp Disaster Med 2017;32:321-8.

12 Arbon P, Cusack L, Ranse J, et al. Exploring staff willingness to attend work during a disaster: a study of nurses employed in four Australian emergency departments. Australas Emerg Nurs $J$ 2013;16:103-9.

13 Ejeta LT, Ardalan A, Paton D. Application of behavioral theories to disaster and emergency health preparedness: a systematic review. PLoS Curr 2015;7. doi:10.1371/currents.dis.31a8995ced321301466d b400f1357829

14 Chokshi NK, Behar S, Nager AL, et al. Disaster management among pediatric surgeons: preparedness, training and involvement. Am J Disaster Med 2008;3:5-14.

15 Burke RV, Goodhue CJ, Chokshi NK, et al. Factors associated with willingness to respond to a disaster: a study of healthcare workers in a tertiary setting. Prehosp Disaster Med 2011;26:244-50.

16 Charney RL, Rebmann T, Flood RG. Hospital employee willingness to work during earthquakes versus pandemics. J Emerg Med 2015;49:665-74.

17 Balicer RD, Omer SB, Barnett DJ, et al. Local public health workers' perceptions toward responding to an influenza pandemic. BMC Public Health 2006;6:99.

18 Shapira S, Aharonson-Daniel L, Bar-Dayan Y, et al. Knowledge, perceptions, attitudes and willingness to report to work in an earthquake: a pilot study comparing Canadian versus Israeli Hospital nursing staff. Int Emerg Nurs 2016;25:7-12.

19 Bandura A. Self-efficacy: the exercise of control. Macmillan, 1997.

20 Arbon P, Ranse J, Cusack L, et al. Australasian emergency nurses' willingness to attend work in a disaster: a survey. Australas Emerg Nurs J 2013;16:52-7.

21 Brice JH, Gregg D, Sawyer D, et al. Survey of hospital employees' personal preparedness and willingness to work following a disaster. South Med J 2017;110:516-22.

22 United Nations Office for the Coordination of Humanitarian Affairs. Humanitarian Bulletin Yemen/ health system on the verge of collapse, 2015. Available: http://reliefweb.int/report/yemen/yemenhumanitarian-bulletin-issue-6-issued-30-november-2015-enar

23 Qirbi N, Ismail SA. Health system functionality in a low-income country in the midst of conflict: the case of Yemen. Health Policy Plan 2017;32:911-22.

24 United Nations - Headquarters. Sendai framework for disaster risk reduction 2015-2030. United nations office for disaster risk reduction, 2015. Available: https://www.unisdr.org/we/inform/ publications/43291

25 Loke AY, Fung WMO, Liu X. Mainland China nurses' willingness to report to work in a disaster. Am J Disaster Med 2013;8:273-82.

26 Al Khalaileh MA, Bond E, Alasad JA. Jordanian nurses' perceptions of their preparedness for disaster management. Int Emerg Nurs 2012;20:14-23.

27 Alzahrani F, Kyratsis Y, Yiannis K. Emergency nurse disaster preparedness during mass gatherings: a cross-sectional survey of emergency nurses' perceptions in hospitals in Mecca, Saudi Arabia. BMJ Open 2017;7:e013563.

28 Ogedegbe C, Nyirenda T, Delmoro G, et al. Health care workers and disaster preparedness: barriers to and facilitators of willingness to respond. Int J Emerg Med 2012;5:29.

29 Stergachis A, Garberson L, Lien O, et al. Health care workers' ability and willingness to report to work during public health emergencies. Disaster Med Public Health Prep 2011;5:300-8. 